\title{
Sustainable management of waste in green nursery: the Tuscan experience
}

\author{
Daniele Sarri, Riccardo Lisci, M. Rimediotti, M. Vieri \\ Department of Agricultural, Food Production and Forest Management University of Florence \\ Firenze, Italy
}

\begin{abstract}
The green nursery sector in Europe involves 90,000 ha of cultivated land and 120,000 ha for the nurseries (MiPAAF, 2012), reaching 19.8 billions of Euros in 2011. Every year, nurseries produce waste about 4 $\mathrm{kg}$ of the residual biomass for each $\mathrm{m}^{2}$ of the potted plants cultivation.

Nurseries waste make up a substantial quantity of organic materials e.g. wood biomass-substrate, which could be retrieved and valorized. With the expansion of potted plants cultivation and the resulting increase in discarded products a number of companies have begun to setting up solutions for the recovery of materials accumulated.

Analysis led to the development of a separating system based on trunk vibration technology. To this end, two shaker yard were identified, developed and tested for the recovery of residual biomasses. With these solutions, green waste can be easily grasped by a clamp device able to convey strong vibrations to the trunk (or to the aerial part of the plant) to the point that the soil materials are detached from the vegetable portions.
\end{abstract}

Correspondence: Daniele Sarri, GESAAF Department of Agricultural, Food Production and Forest Management, Scuola di Agraria, University of Florence, Piazzale delle Cascine 15, 50144 Firenze, Italy

Tel. +39055 3288320 - Fax +39055 331794

E-mail:daniele.sarri@unifi.it

Key words: biomass recovery, substrate reuse, mechanical shaker separation.

Acknowledgments: Authors wish to acknowledge the Vannucci's nursery that hosted the tests and supplied a lot of the information contained in the present work filling in specific questionnaires. Furthermore, authors wish to thank the company A. Spedo e Figli for the logistic assistance and the cooperation.

Contributions: the authors contributed equally.

Conflict of interests: the authors declare no potential conflict of interests.

Funding: the work was supported by Regione Toscana, project VIS Vivaismo Sostenibile 2013.

@CCopyright Da. Sarri et al., 2013

Licensee PAGEPress, Italy

Journal of Agricultural Engineering 2013; XLIV(s2):e28

doi:10.4081/jae.2013.s2.e28

This article is distributed under the terms of the Creative Commons Attribution Noncommercial License (by-nc 3.0) which permits any noncommercial use, distribution, and reproduction in any medium, provided the original author(s) and source are credited.

\section{Introduction}

The Italian nursery sector involves 13,000 ha of potted flowers and plants and represent the second most important European market with an annual average turnover of 2,5 billions of Euros.

Although the significant economic potential, the sector is characterised either by limited size companies, i.e. less than $10.000 \mathrm{~m} 2$ and, either by a limited number of extensive nurseries. Consequently, these conditions, influence the potential level of innovation that the companies choose and that could implement. The small nursery employ standard stage processes and mechanization, vice versa the big companies, in the last years, started to implement innovative solutions in the productive processes. Many studies developed in Oregon (CFNP, 2011) analyse the impacts associated to the nurseries, recommending best practices for energy reductions and wastes recycle or reuse. Furthermore, the worldwide financial crisis and the rising cost of raw materials, has also affected the nursery sector specifically for the supply of raw materials such peat (basic element of the substrates) and mineral fertilizers.

About this the University of Florence research unit worked on the VIS (Sustainable Plant Nurseries Project) on a study to identify solutions for the green nursery wastes recovery. Green waste products in nurseries and the derivatives of dried and unsalable plants, of lifting plants and pruning, make up a substantial quantity of organic materials e.g. wood biomass and substrate, which could be retrieved and valorized. The wastes of farm that works on full field cultivations, are usually made up of dried plants and pruning byproducts while the reverse is the case for those raising crops in containers, whose waste is mainly substrate. Moreover, the latter fraction shows a high concentration of controlled-release-fertilizers, which gives great potential and high economic value to the recycled substrate (Figure 1). Up to few years ago, the common management was carried out through the disposing of all the biomass, i.e. the wood, the roots, the substrate and other waste materials. With the expansion of cultivating crops in containers and the resulting increase in discarded products a number of companies have begun setting up work-sites for the management of the materials accumulated. Currently, for wastes recovery, the most widespread technique is to sent the biomass to a treatment plant where shredding and wind separating are performed, producing powdery substrate, wood with substrate traces, iron and stony materials. The powdery substrate may be mixed with the virgin substrate with a variable share, whilst the wood is used for biofilters production. Another type of management involves the biomass shredding and a storage phase with a variable duration in function of the weather, features of the stock site, raw matter quality, type and number of processing stages. This management ensures a fermentation of the biomass with a potential reduction of the pests level. However, the resulting biomass, has a more concentration of wood parts than the other one.

The components which can be recovered on industrial work-sites following bioshredding take on characteristics which make it difficult to get two fractions of optimum quality (Figure 2). This operations are more effective if the different typologies of the residual biomass (i.e. 
the wood and the substrate) are separated, before the shredding phase, in order to guarantee their better reuse and a more significant substitution of the raw materials needed in the nursery. Particularly, depending on the level of separation of the main components and on the quality of the recovered products in terms of purity, size, etc., the shredded wood may be applied as biofilter or as solid biofuels. The recovered substrate may be mixed to the virgin one in quantities as higher as the wood and the other minor compounds (e.g. stones, ferrous materials, plastics, etc.) are much limited.

On these bases, the work has focused to identify solutions for separating substrate and wood biomass components with processes, which do not allow interaction. Analysis led to the development of a separating system based on trunk vibration technology.

\section{Materials and methods}

The concept singled out is based on the knowledge that the biomass, to be worked, must be moved in any case in the nursery. On this basis a solution able to simultaneously perform the step of handling and separation was defined. The general principle is: the biomass may be easily grasped by a clamp device able to convey strong vibrations to the trunk to the point that the substrate is detached from the vegetable portions. In so doing the two components can be managed separately, as green discard and earth-peat for reusing in the production process. Then the whole plant is chipped obtaining wood that may be used as solid biofuel in small or medium sized boilers for heating. The recovered substrate may be used instead of the virgin one. To this end, two yards were identified, developed and tested for an efficient use on residual biomass with a mass of up to $800 \mathrm{~kg}$.

Selected as a solution to apply in smaller nurseries with plants of no more than $100 \mathrm{~kg}$ was a small yard "Unifi prototype" made of a tracklaying walking tractor equipped with a shaker clamp with a motorized frame equipped with power points and a lift (Figure 3 ). The drive transmission is hydrostatic: a tandem pump is connected to the engine, which in its turn controls two orbital motors with direct power take-off from the cog wheels; the control unit for forward movement and the steering is the only lever, so the vehicle can be driven with one hand. Speed variation is continuous up to a maximum of $6 \mathrm{~km} / \mathrm{h}$ both forward and in reverse.

The clamp weigh about $100 \mathrm{~kg}$ and is coupled with the closure jaws for work on trees of up to $150 \mathrm{~mm}$ in diameter. The vibration is made by an eccentric mass driven by an hydraulic motor; this configuration, with a $16 \mathrm{~cm}^{3}$ hydraulic motor, produces centrifugal force of vibration about $120 \mathrm{~N}$ at the frequency of $69 \mathrm{~Hz}$. Hydraulic plant, with a capacity of $45 \mathrm{~L} \mathrm{~min}^{-1}$, is required for operations. Moreover, the prototype is furnished with a setup for the shaker that includes a steel frame, for regulating and positioning the vibrating jaws. The movement of the vibrating clamp is driven by a horizontal forked boom with manual regulation equipped with a hydraulic piston linking it to the lift column, also with a hydraulic control lever. With this configuration, the clamp can be positioned from $0,3 \mathrm{~m}$ to $1 \mathrm{~m}$ above the mean ground elevation and a further $0,5 \mathrm{~m}$ with the regulation for inclination. Used for handling plants with mass of more than $100 \mathrm{~kg}$ is the vibrating clamp made by the company A. Spedo e Figli in Badia Polesine, near Rovigo, capable of dealing with trees with masses of up to $800 \mathrm{~kg}$ and diameters of up to $0,4 \mathrm{~m}$. The technical specification of the yard make it possible to cope with all types of plant discards which can be found a nursery. For this purpose, the yard includes a $110 \mathrm{~kW}$ tractor equipped with a front loader and the clamp (Figure 4). This configuration is a solution suitable for medium size and big nurseries or contractor services. The vibrating clamp, with opposing jaws, is oil hydraulic driven. By the rota-

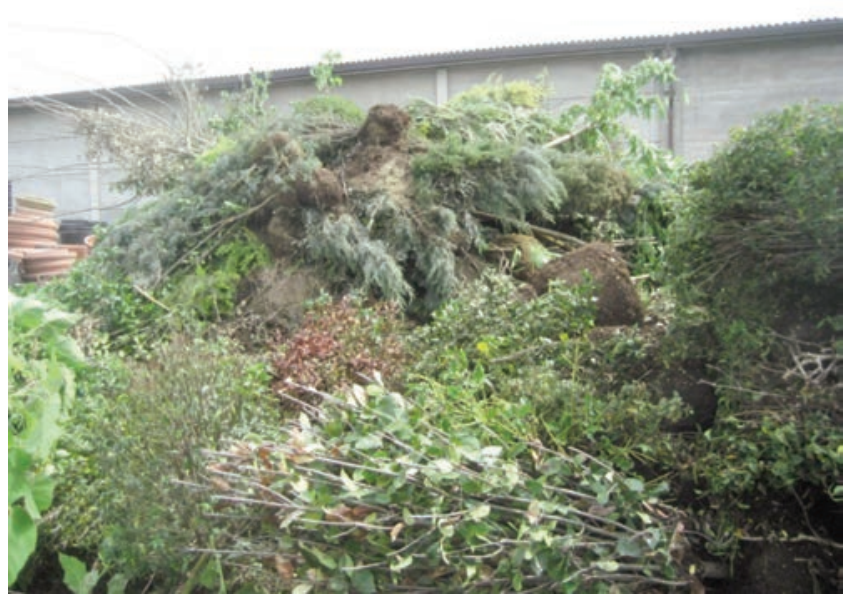

Figure 1. Green nursery waste: pile of discarded plants.

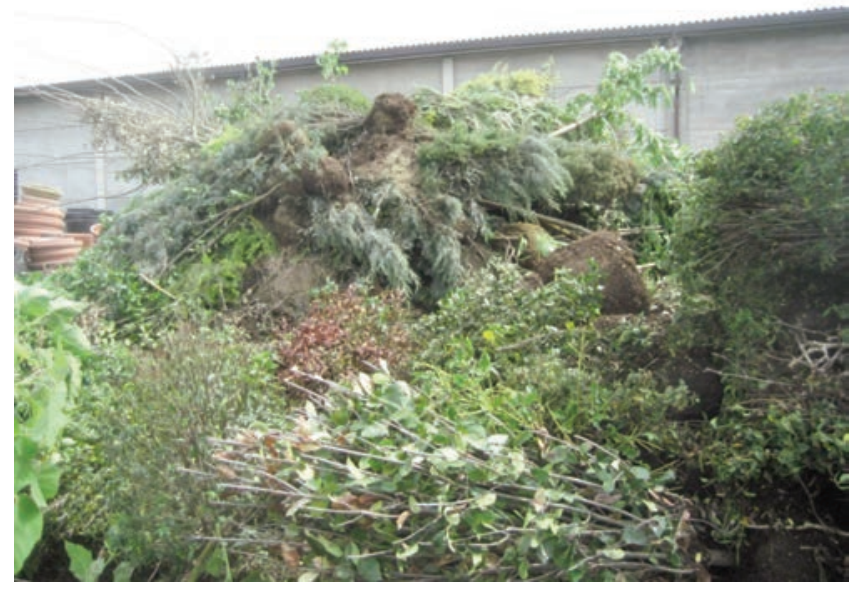

Figure 2. Green waste after the bio-shredding phase: the two fractions present a high level of contamination.

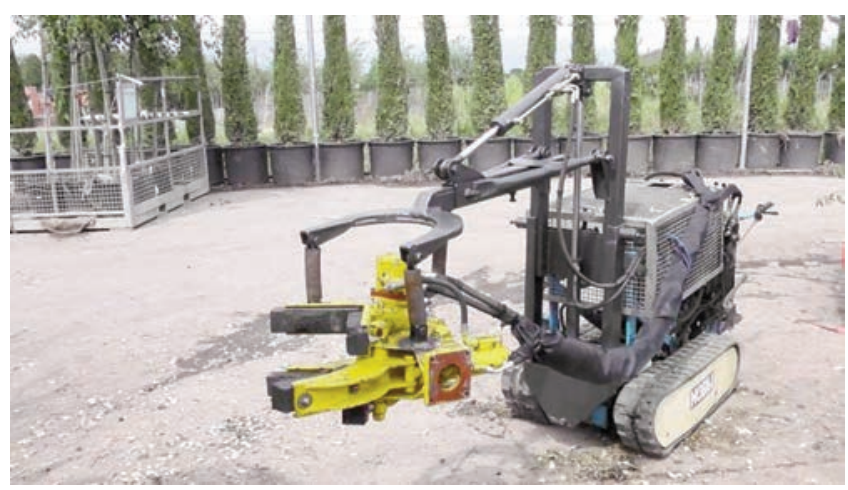

Figure 3. The "Unifi prototype" made of a small track-laying walking tractor equipped with a shaker clamp. 
tion of an inertial mass driven by a hydraulic motor, it originates a variation of centrifugal strength, which in its turn generates vibration. Micro-vibration can be regulated for amplitude and frequency and is controlled independently of the shaker on the basis of the diameter of the tree gripped to ensure the complete detachment of the soil. The design configuration enables rotation of $60^{\circ}$ for facilitating gripping and moving the tree. The jaws are easy for the operator to maneuver with great precision and safety through a joystick in the tractor cab or report control and the electro-hydraulic device enabling movement at

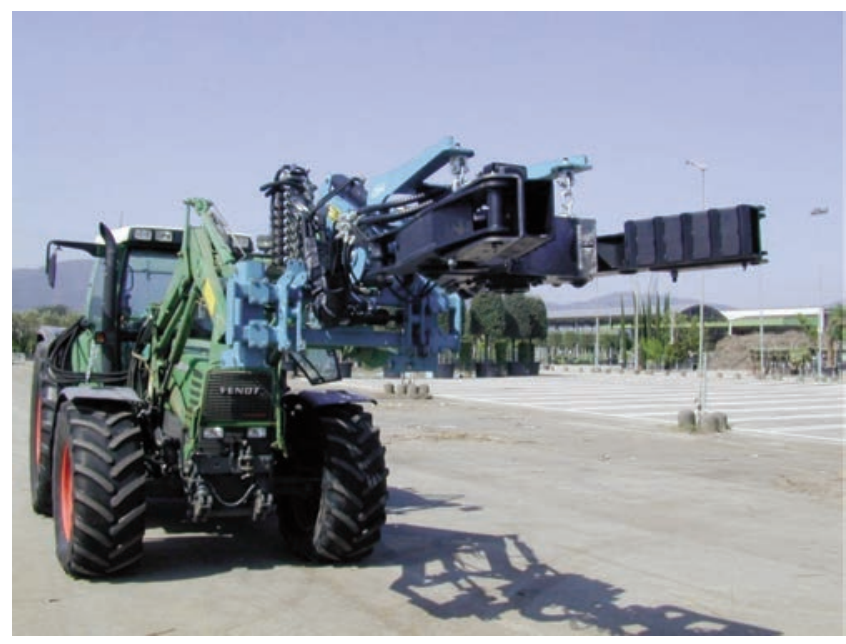

Figure 4. The implemented yard based on a shaker A. Spedo e Figli company. proportional speeds. The original closing clamps on the jaws were modified with the addition of structures and raised steel staffs for a steady grip during shaking. The logistics for operations call for the following phases: gripping the tree, recovery of the containers, shaking, heaping up the biomass. (Figure 5) Work on the single tree appears laborious but it must be pointed out that this operation does not entail further steps because with present management each tree is gripped and lifted with a lift for the container recovery.

To study the effectiveness of the yards, some tests were conducted in the Vannucci Green Nursery Company in the city of Pistoia located in the centre of Italy. The field tests were performed with two types of green waste species: $x$ Cupressocyparis leylandii commonly called Leyland Cypres and Cedrus atlantica "Glauca Pendula" commonly called Weeping Atlas Cedar. The first specie tested were raised 5 years in containers of $50 \mathrm{~L}$ and they had a single trunk height $3,5 \mathrm{~m}$ on average. The Weeping Atlas Cedar, were raised in container, with variable volumes from 240 to $300 \mathrm{~L}$ of substrate for the same time, they had reached $4,5 \mathrm{~m}$ in height and they were structured in single trunk with the upper part curved to the ground. The average trunk diameters, of the two tree kinds, were respectively $0,065 \mathrm{~m}$ for the Leyland Cypres and $0.1 \mathrm{~m}$ for the Weeping Atlas Cedar.

Trials were carried out on twenty trees by applying the force to the trunk at an approximate height of $0.1 \mathrm{~m}$ from the upper level of the substrate. The UNIFI prototype worked only the species Leyland Cypres because it is designed to work with biomasses with maximum mass of $100 \mathrm{~kg}$ while the Spedo yard worked both the specie. Each tree was weighed before and after the shaker stage by means of a load cell brand DG model MCWL600 with a sensitivity of $0.05 \mathrm{~kg}$ and full scale at 600 $\mathrm{kg}$. Measurements were performed up to the complete separation the substrate from the wood biomass storing the time required.

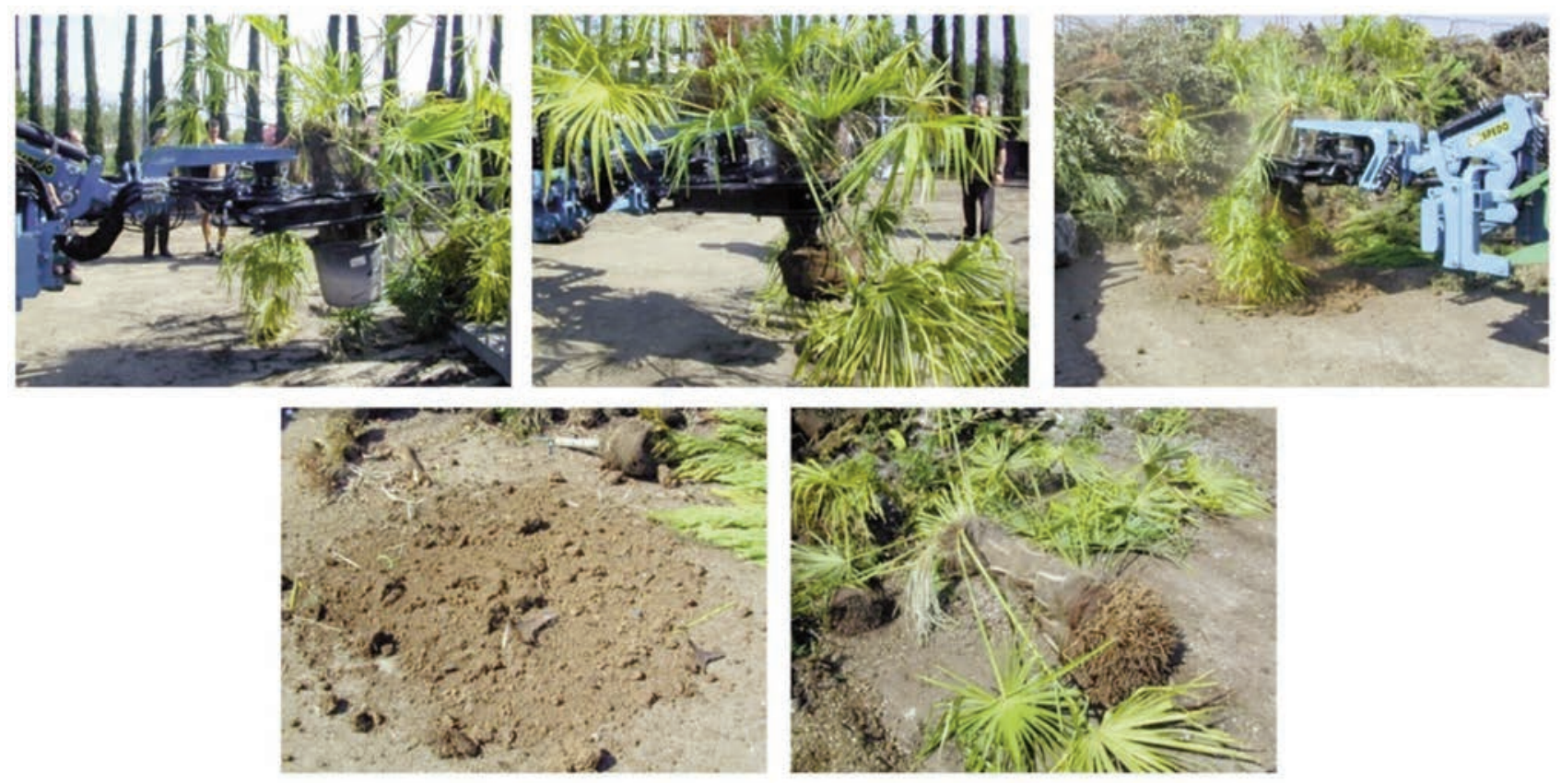

Figure 5. The operative logistics: grip the tree, containers recovery, shaking, heaping up the biomass. 


\section{Results}

Both the yards developed have allowed to effectively separating the residual biomass. The Unifi prototype has employed an average of 34 seconds to work each plant (shaking stage) while the Spedo yard, with the Weeping Atlas Cedar, it took 32 seconds and 31 seconds for the Leyland Cypres. About the quantity of recovery materials, preliminary tests conducted have highlighted for the Weeping Atlas Cedar mean values of $40 \mathrm{~kg}$ of green waste and $250 \mathrm{~kg}$ of substrate. In the case of Leyland Cypres were obtained average values of $18 \mathrm{~kg}$ of green waste and $34 \mathrm{~kg}$ of substrate. Regarding the quality of the recovery portions, in the case of the powdery substrate these were cleaned by the visual point of view with only some leaf and small parts of the root system. The latter appear completely separated from the substrate so immediately ready to the shredding stage. Also the characteristics of the recycled powdery substrate allow to mix instantaneously with the virgin matters, reducing the demand of non-renewable raw material.

\section{Conclusions}

Present work has focused to the possible recovery of the residual biomasses, i.e. the wood and the substrate, of the potted plants that are discarded in the nursery production chain. To recognize the value of green waste, different ways and equipment can be employed, so it is necessary a careful reflection on the design of the more suitable yard in function of the type of nursery. In particular, it is essential to consid- er the available spaces and the economic feasibility: the yards configurations depend by the structural and organizational conditions of the nursery, but also by its investment capability. Other essential variables are the amount of waste produced annually, their features, in terms of botanical species and size of plants. All these aspects affect the choice of machines. The use of shaker machines to residual biomasses recovery is an alternative technique that, properly developed and industrialized, may be effectively introduced in the nursery chain. The adoption of innovative technologies for green waste recovery described in this study can afford on the one hand the exploitation of by-products, on the other to obtain significant benefits in terms of environmental protection thanks to the recovery of biomass for energy purposes.

\section{References}

CFNP, 2011.Climate Friendly Nurseries Project, Best management practices for climate friendly nurseries, Oregon Association of Nurseries, Oregon Environmental Council, Oregon State University, Advantage IQ, Version 2.0, August 2011.

MiPAAF, 2012. Lettera UE 13-05, Situazione attuale del settore florovivaistico Europeo, 19 luglio 2012.

Sarri D, Rimediotti M, Vieri M, Recupero degli scarti verdi Chapter 3 in final report book Gestione sostenibile dei vivai 2013. Available from: http://www.cespevi.it/vis/Manuale_VIS.pdf Accessed: May2013. 